Article

\title{
Identification and Characterization of Tomato SWI3-Like Proteins: Overexpression of SISWIC Increases the Leaf Size in Transgenic Arabidopsis
}

\author{
Zhongyi Zhao ${ }^{1,2,3,+}{ }^{\text {, Tao } \mathrm{Li}^{4,+} \text {, Xiuling Peng }}{ }^{2,5}$, Keqiang $\mathrm{Wu}{ }^{6, *(\mathbb{D})}$ and Songguang Yang ${ }^{2, *(1)}$ \\ 1 Ministry of Education Key Laboratory for Bio-Resource and Eco-Environment, College of Life Science, \\ Sichuan University, Chengdu 610064, China; zzycwnu@163.com \\ 2 Key Laboratory of South China Agricultural Plant Molecular Analysis and Genetic Improvement, \\ Guangdong Provincial Key Laboratory of Applied Botany, South China Botanical Garden, Chinese Academy \\ of Sciences, Guangzhou 510650, China; m13203206354_2@163.com \\ 3 College of Life Sciences, China West Normal University, Nanchong 637002, China \\ 4 Vegetable Research Institute, Guangdong Academy of Agricultural Sciences, Guangzhou 510650, \\ China; tianxing84@163.com \\ 5 University of Chinese Academy of Sciences, Chinese Academy of Sciences, Beijing 100049, China \\ 6 Institute of Plant Biology, National Taiwan University, Taipei 106, Taiwan \\ * Correspondence: yangsongguang@scbg.ac.cn (S.Y.); kewu@ntu.edu.tw (K.W.) \\ + These authors contributed equally to this work.
}

Received: 12 September 2019; Accepted: 10 October 2019; Published: 16 October 2019

\begin{abstract}
As the subunits of the SWI/SNF (mating-type switching (SWI) and sucrose nonfermenting (SNF)) chromatin-remodeling complexes (CRCs), Swi3-like proteins are crucial to chromatin remodeling in yeast and human. Growing evidence indicate that AtSWI3s are also essential for development and response to hormones in Arabidopsis. Nevertheless, the biological functions of Swi3-like proteins in tomato (Solanum lycopersicum) have not been investigated. Here we identified four Swi3-like proteins from tomato, namely SISWI3A, SISWI3B, SISWI3C, and SISWI3D. Subcellular localization analysis revealed that all SISWI3s are localized in the nucleus. The expression patterns showed that all SISWI3s are ubiquitously expressed in all tissues and organs, and SISWI3A and SISWI3B can be induced by cold treatment. In addition, we found that SISWI3B can form homodimers with itself and heterodimers with SISWI3A and SISWI3C. SISWI3B can also interact with SIRIN and SICHR8, two proteins involved in tomato reproductive development. Overexpression of SISWI3C increased the leaf size in transgenic Arabidopsis with increased expression of GROWTH REGULATING FACTORs, such as GRF3, GRF5, and GRF6. Taken together, our results indicate that SISWI3s may play important roles in tomato growth and development.
\end{abstract}

Keywords: Swi3-like proteins; gene expression; protein interaction; leaf development; tomato

\section{Introduction}

The fundamental unit of chromatin is the nucleosome, which is composed of two turns of DNA wrapped around a histone octamer (two H2A-H2B dimers and one H3-H4 tetramer) [1]. To readout genomic information, a dynamic chromatin environment is needed during the cellular processes such as transcription, DNA replication and recombination. The modification of chromatin can occur through multiple mechanisms, including nucleosome composition and positioning by ATP-dependent chromatin-remodeling complexes (CRCs) and enzyme complexes that modify DNA or chromatin proteins [2,3]. CRCs use energy from ATP hydrolysis [4] and change local chromatin structure, thus enriching accessibility of transcription factors and availability of genomic information [5]. 
The first CRC, SWI/SNF CRC, was identified in two independent screens for mutants affecting mating-type switching (SWI) and growth on sucrose (sucrose nonfermenting, SNF) in yeast $[6,7]$. Biochemical analysis indicated that yeast SWI/SNF CRC is composed of 12 subunits [8], and the core complex including SWI2/SNF2-type ATPase, one SNF5, and two copies of SWI3 subunits, is sufficient for execution of nucleosome remodeling in vitro [9]. Moreover, several accessory subunits associating with the core complex act as an interface for interactions with other auxiliary proteins that affect chromatin remodeling activity [10].

As part of SWI/SNF CRC, yeast Swi3p is essential for the assembly of this complex, ATP-dependent H2A-H2B displacement and recruitment to target genes [11,12]. Further genome analysis indicated that Swi3-like proteins are found in virtually all eukaryotes, such as Drosophila, mammals and Arabidopsis. Intriguingly, studies in both yeast and mammalian cells showed that Swi3p and its mammalian homologs BAF155 and BAF170 can target many genes and genomic locations in the absence of Swi2 and other components of the SWI/SNF CRC complex [13,14], suggesting that they may have unique functions in gene regulation. Generally, all Swi3-like proteins contain two typical domains, the SWIRM and SANT domains. The SWIRM domain (Swi3p, Rsc8p, and Moira) consists of 85 amino acid residues and forms a compact helix-turn-helix (HTH)-related structure [15], while the SANT (SWI3, ADA2, N-CoR and TFIIIB) domain is structurally related to the homeodomain and the Myb DNA-binding domain [16]. Furthermore, in addition to Swi3-like proteins, the SWIRM domain is also found in LSD1 (Lysine-specific demethylase 1), Ada2 (Adenosine deaminase isoenzymes 2), and in a JAB domain-containing protein involved in protein degradation through the ubiquitin pathway [15]. Functional analysis demonstrated that SANT domains tether to both DNA and proteins and are essential for histone acetyltransferase activity [16,17].

In Arabidopsis, four Swi3-like proteins, namely CHB1 (AtSWI3A), CHB2 (AtSWI3B), CHB3 (AtSWI3C) and CHB4 (AtSWI3D), have been identified [18,19]. Current data show that they operate as modifiers of transcriptional or epigenetic regulation in plant growth and development. For example, mutations of AtSWI3A and AtSWI3B result in disruption of embryo development at the globular stage, while mutations in AtSWI3C and AtSWI3D display severe dwarfism, abnormal vegetative development, and reduced fertility [20]. Moreover, yeast-two-hybrid assays demonstrated that AtSWI3A and AtSWI3B can form homodimers and heterodimers, and also interact with BSH/SNF5, AtSWI3C, and the flowering regulator FCA, while AtSWI3D can only bind AtSWI3B $[18,20]$. Interestingly, when expressed in Saccharomyces cerevisiae, AtSWI3B can partially complement the swi3 mutant phenotype [18]. In addition to interacting with other SWI3 subunits, AtSWI3B also interacts with HYPERSENSITIVE TO ABA1 (HAB1), a negative regulator of ABA signaling, indicating that SWI3B is involved in the ABA signaling [21]. Subsequent research found that AtSWI3B physically interacts with IDN2, a lncRNA-binding protein, and contributes to lncRNA-mediated transcriptional silencing [22]. Recent data demonstrated that AtSWI3B (as well as AtSWI3C and AtSWI3D) interacts with MORC6 (MICRORCHIDIA 6) and a SET domain-containing histone methyltransferase SUVH9 (SU(VAR)3-9 homolog) to mediate transcriptional silencing [23].

In leaf development, the expression of IAMT1 (IAA Carboxyl Methyltransferase 1) is regulated by AtSWI3B-mediated chromatin remodeling [24]. In addition to auxin and ABA, the Arabidopsis Swi3-like proteins are also involved in other hormone signaling. For instance, the AtSWI3C mutation down-regulates the expression of GID1 GA receptor genes, affecting the GA perception in leaves [25]. Meanwhile, AtSWI3C physically interacts with several DELLA proteins, indicating that chromatin remodeling mediated by AtSWI3C may be required for the DELLA-mediated effects, such as activation of GID1 [25]. Moreover, the AtSWI3C (as well as AtSWI3D)-containing SWI/SNF chromatin remodeling complex is recruited by the transcriptional coactivator AN3 (ANGUSTIFOLIA3) to the promoters of leaf development related genes [26]. Consistently, modification of the AtSWI3C expression increases leaf size by increasing cell number but not cell size [26]. Moreover, recent data indicated that ZmCHB101, one of three maize SWI3D genes, plays essential roles in maize growth and development at both 
vegetative and reproductive stages [27], since the ZmCHB101 RNA interference plant lines displayed abaxially curling leaf and impaired tassel and cob development phenotypes.

Compared to Arabidopsis, the functions of Swi3-like proteins are largely unknown in other plant species. Nevertheless, phylogenetic analysis indicated that the Swi3-like proteins are widely present in the genomes of other plant species such as rice (Oryza sativa), Medicago truncatula and Zea mays [28]. In this study, we identified and characterized four Swi3-like proteins, namely SISWI3A, SISWI3B, SISWI3C, and SISWI3D, in tomato (Solanum lycopersicum). The expression profiles and subcellular localization of tomato Swi3-like proteins were investigated. In addition, the interaction of Swi3-like proteins with RIN and SICHR8, two proteins involved in reproductive development, was also explored. Furthermore, ectopic expression of SISWI3C in Arabidopsis resulted in the increased leaf size. Taken together, our results shed light on the potential functions of Swi3-like proteins during tomato development.

\section{Results}

\subsection{Identification and Phylogenetic Analysis of Tomato Swi3-Like Proteins}

The Swi3-like proteins sequences of Arabidopsis, rice, yeast and human were used as queries to search against the SGN annotation database with the BLAST program. All sequences with an E-value below $10^{-2}$ were selected for further analysis. Pfam and SMART databases were used to confirm each candidate protein sequence. Like Arabidopsis, four Swi3-like proteins (namely SISWI3A, SISWI3B, SISWI3C, and SISWI3D) were identified in the tomato genome (Table 1). The open reading frames (ORFs) of SlSWI3s ranged from 1470 to $2838 \mathrm{bp}$, and the length of SISWI3 proteins varied from 490 to 946 amino acids. Further bioinformatics analysis indicated that SISWI3 proteins were potentially localized in different organelles including the nucleus, cytoplasm, chloroplast and mitochondria (Table 1).

To further investigate the evolutionary relationships of SISWI3, we carried out phylogenetic analyses using Swi3-like proteins of different species. The phylogenetic tree indicated that the plant Swi3-like proteins can be clearly divided into four groups: SWI3A, SWI3B, SWI3C, and SWI3D, while the SWI3A/SWI3B pairs are more related to the branches of yeast and animal Swi3 sequences (Figure 1A). The conserved domain analyses showed that all Swi3-like proteins contain two characteristic domains: SWIRM and SANT domains (Figure 1B). Moreover, the SWIRM-assoc_1 (SWIRM-associated region 1) domain (Interpro: IPR032451), which was previously identified as the leucine zipper domain [20], was found in all members of Swi3-like proteins except for SISWI3B (Figure 1B). Like the AtSWI3D and OsSWI3Ds, a ZnF_ZZ domain (Interpro: IPR000433), which was named because of the ability to bind two zinc ions [29], was also found in the N-terminus of SISWI3D. In general, ZZ-type zinc finger domains contained 4-6 Cys residues that participate in zinc binding as well as protein-protein interaction [30]. 
Table 1. The SWI3-like proteins in Tomato, Arabidopsis and rice.

\begin{tabular}{|c|c|c|c|c|c|c|c|c|}
\hline $\begin{array}{l}\text { SWI3 Gene } \\
\text { Family }\end{array}$ & Gene Name & Gene Code & $\begin{array}{l}\text { Accession } \\
\text { Number }^{\mathrm{a}}\end{array}$ & ORF Length ${ }^{b}$ & Protein Length & Localization ${ }^{c}$ & $\begin{array}{c}\text { Number of } \\
\text { Exons }\end{array}$ & $\begin{array}{c}\text { Nuclear } \\
\text { Localization } \text { Signal }^{\mathrm{d}}\end{array}$ \\
\hline \multirow[t]{3}{*}{ SWI3A } & SISWI3A & Solyc03g097450 & XP_004235292 & 1772 & 574 & nucl, cyto & 7 & Yes \\
\hline & AtSWI3A & AT2G47620 & NP_850476 & 1539 & 513 & nucl, cyto & 7 & Yes \\
\hline & OsSWI3A & LOC_Os04g40420 & BAF15014 & 1683 & 561 & nucl, cyto, plas & 7 & Yes \\
\hline \multirow[t]{3}{*}{ SWI3B } & SISWI3B & Solyc04g082760 & XP_004238459 & 1470 & 490 & nucl, cyto & 6 & Yes \\
\hline & AtSWI3B & AT2G33610 & NP_180919 & 1410 & 469 & nucl, cyto & 6 & Yes \\
\hline & OsSWI3B & LOC_Os02g10060 & XP_015625317 & 1536 & 512 & nucl & 6 & Yes \\
\hline \multirow[t]{4}{*}{ SWI3C } & SISWI3C & Solyc06g060120 & XP_004242041 & 2376 & 792 & nucl, chlo, mito & 8 & Yes \\
\hline & AtSWI3C & AT1G21700 & NP_173589 & 2424 & 807 & nucl, chlo, plas & 9 & Yes \\
\hline & OsSWI3C1 & LOC_Os12g07730 & ABA96607 & 2520 & 840 & nucl, chlo, mito & 9 & Yes \\
\hline & OsSWI3C2 & LOC_Os11g08080 & XP_015617508 & 2355 & 785 & nucl, chlo, mito & 9 & Yes \\
\hline \multirow[t]{4}{*}{ SWI3D } & SlSWI3D & Solyc01g109510 & XP_004230866 & 2838 & 946 & nucl & 6 & Yes \\
\hline & AtSWI3D & AT4G34430 & NP_974682 & 2961 & 986 & nucl & 7 & Yes \\
\hline & OsSWI3D1 & LOC_Os03g51220 & XP_015632283 & 2745 & 915 & nucl, cyto & 8 & Yes \\
\hline & OsSWI3D2 & LOC_Os04g01970 & XP_015633469 & 2661 & 887 & nucl, chlo, mito & 7 & Yes \\
\hline
\end{tabular}

${ }^{a}$ Accession numbers of full-length protein sequence available at NCBI (https://www.ncbi.nlm.nih.gov/). ${ }^{\mathrm{b}}$ Length of open reading frame (number of basepair). ${ }^{\mathrm{c}}$ Localization of tomato SWI3-like proteins supported by WoLFPSORT (http://www.genscript.com/psort/wolf_psort.html), Plant-mPLoc (http://www.csbio.sjtu.edu.cn/bioinf/plant-multi/\#) and Euk-mPLoc 2.0 (http://www.csbio.sjtu.edu.cn/bioinf/euk-multi-2/). All SWI3-like proteins of plants was localized in the nucleus using Plant-mPLoc and Euk-mPLoc 2.0 programs. cyto, cytoplasm; nucl, nucleus; Plas, plasmamembrane; mito, mitochondrion; chlo, chloroplast. ${ }^{\mathrm{d}}$ Nuclear localization signal prediction based on frequent pattern mining and linear motif scoring using SeqNLS (http://mleg.cse.sc.edu/seqNLS/) and NucPred (https://nucpred.bioinfo.se/cgi-bin/single.cgi) programs. 
A

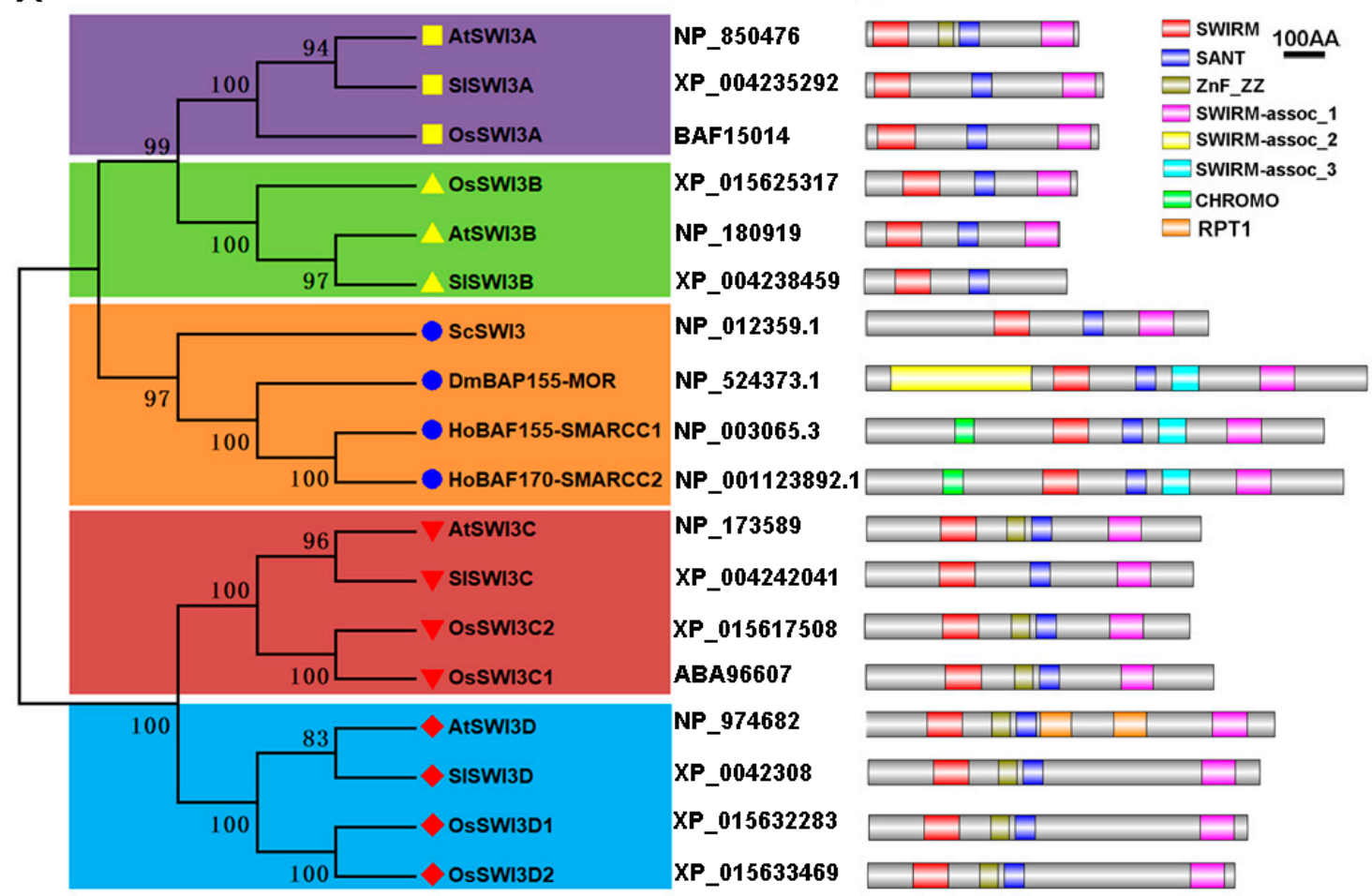

Figure 1. Phylogenetic tree and domain architecture of SISWI3s in tomato. (A) Phylogenetic tree of Swi3-like proteins in plants and animal. Neighbor-joining (NJ) phylogenetic tree for SWI3s in S. cerevisiae (Sc), D. melanogaster (Dm), H. sapiens (Ho), A. thaliana (At), and S. lycopersicum (Sl). The groups of homologous genes identified, bootstrap values and accession numbers are shown. The reliability of branching was assessed by the bootstrap resampling method using 1000 bootstrap replicates. (B) Domain architecture of the Swi3-like proteins was drawn by DOG2.0. according to analysis by SMART and PFAM searches. The location of domains is shown by different color as indicated. The scale represents the length of the protein and all proteins are displayed in proportion. The proteins belonging to each family are grouped together.

\subsection{Subcellular Localization of Tomato Swi3-Like Proteins}

Bioinformatics analysis showed that SISWI3 proteins exhibit various patterns of subcellular localization (Table 1). Nevertheless, a previous study demonstrated that Arabidopsis AtSWI3B localizes at the nucleus [21]. To determine the subcellular localization of tomato Swi3-like proteins, we performed in vivo targeting experiments in tobacco (N. benthamiana). To this end, SISWI3A, SISWI3B SISWI3C and SISWI3D were subcloned into the pEAQ-GFP vector to generate 35S: SISWI3A-GFP, 35S: SISWI3B-GFP, 35S: SISWI3C-GFP and 35S: SISWI3D-GFP constructs, respectively. The constructs were introduced into leaf cells of tobacco by A. tumefaciens infiltration [31]. The fluorescence was visualized through a laser-scanning confocal microscope, and DAPI staining was used to visualize nuclei localization. We found that the $N$. benthamiana epidermal cells exhibited strong fluorescence in the nuclei (Figure 2, Figure S1), suggesting that the tomato SISWI3-like proteins are nuclear proteins. 


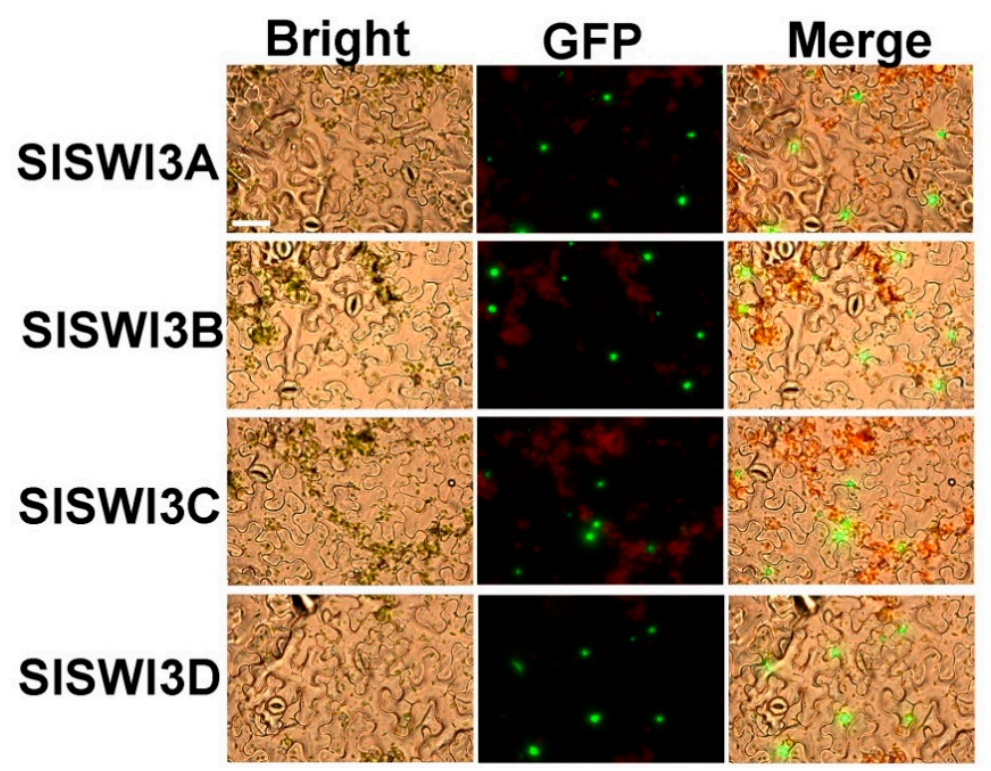

Figure 2. Subcellular localization of SISWI3s. A. tumefaciens strain GV3103 harboring SlSWI3s-GFP constructs were infiltrated into young but fully expanded leaves of tobacco. After growth at $23{ }^{\circ} \mathrm{C}$ for $48 \mathrm{~h}$, the epidermis of tobacco leaves were used to determine the distribution of the fusion protein using a confocal fluorescence microscope. The MADS-box transcriptional factor SIRIN was used as a positive control for localization of a nuclear protein. Bars $=50 \mu \mathrm{m}$. Similar results were obtained in three independent experiments, and one representative result was shown.

\subsection{The Expression Patterns of Tomato Swi3-Like Genes}

In order to explore the possible roles of SlSWI3s, we first analyzed their tissue and organ specific expression profiles from publicly available RNA-seq datasets [32]. As shown in Figure 3A, the transcripts of all SISWI3s were ubiquitously expressed in all tissues and organs. SISWI3C and SISWI3D had similar expression profiles and were expressed mainly in roots $(\mathrm{R})$ and fruits from $1 \mathrm{~cm}$ to 10-day post breaker $(B+10)$ stages (Figure $3 A$ ), suggesting that these genes may play redundant roles in root and fruit development. SISWI3B showed a high expression in buds (B), flowers (F), roots $(\mathrm{R})$ and $\mathrm{B}+10$ fruits, but its expression was low in other tissues. Compare with other SlSWI3s, the expression level of SISWI3A was low in all tissues, especially in leaves (L) and B +10 fruits (Figure 3A). Indeed, all SISWI3s displayed low expression patterns in L compared with other tissues (Figure 3A).

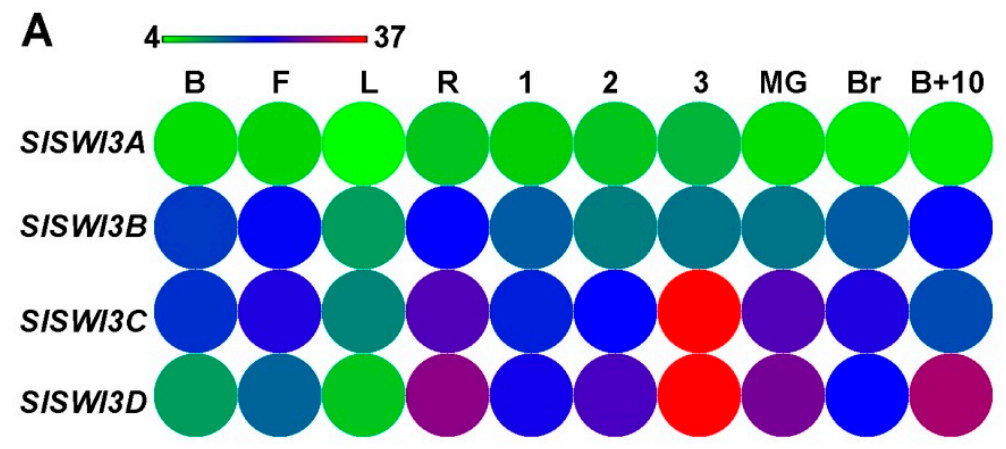

Figure 3. Cont. 


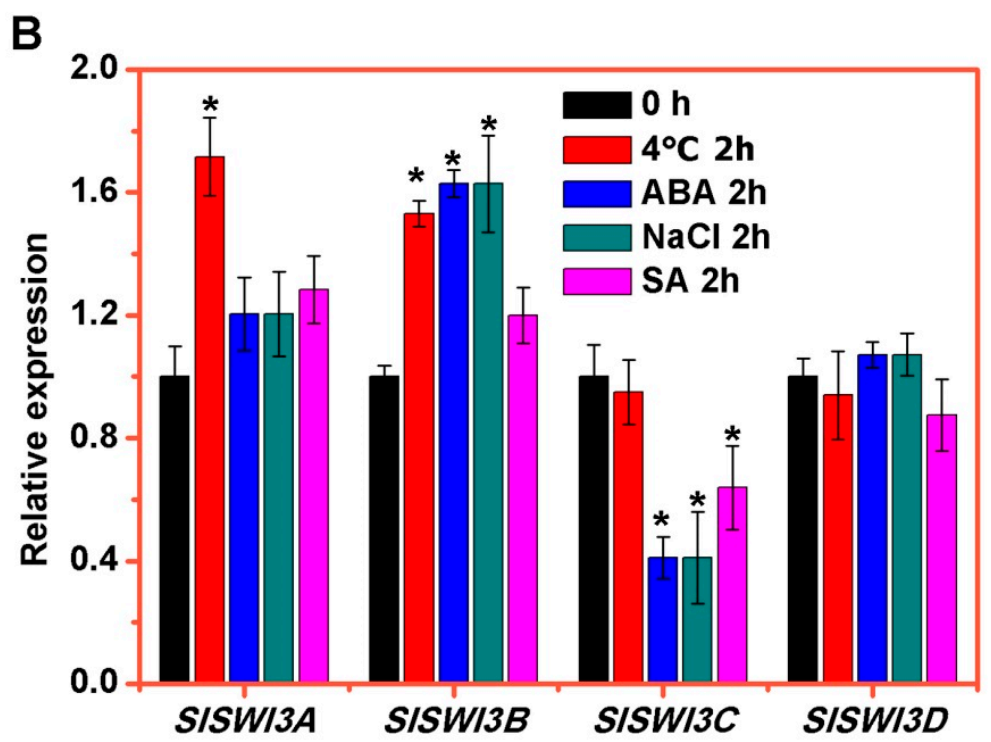

Figure 3. The expression patterns SISWI3s. (A) Tissue-specific expression patterns of SISWI3s. Heat map of RNA-seq expression data from bud (B), flower (F), leaf (L), root (R), 1 cm_fruit (1), 2cm_fruit (2), $3 \mathrm{~cm}$ _fruit (3), mature green fruit (MG), berry at breaker stage (Br), and berry ten days after breaking (B $+10)$. The expression values are measured as reads per kilobase of the exon model per million mapped reads (RPKM). (B) Expression profiles of SISWI3s under responding to hormones, salt, and cold tested by qRT-PCR. Seedlings of two-week-old plate-cultured plants were treated with SA ( $2 \mathrm{mM}), \mathrm{ABA}(100 \mu \mathrm{M})$, $\mathrm{NaCl}(200 \mathrm{mM})$, and cold $\left(4{ }^{\circ} \mathrm{C}\right)$ for $2 \mathrm{~h}$ and collected for total RNA isolation. qRT-PCR was amplified using gene-specific primers. The tomato ACTIN (Solyc03g078400) was used as an internal control. Error bars indicate the SE. Asterisks indicate significant difference from wild-type plants $(p<0.05$, Student's $t$ test). The data are representative from three independent experiments.

Next, we investigated the expression pattern of SISWI3s in response to environmental stimuli including hormones, salt, and cold by qRT-PCR. SISWI3A and SISWI3B were clearly induced by cold treatment, and SISWIBB was also induced by ABA and salt treatments (Figure 3B). The transcript of SISWI3C was strongly repressed by ABA, salt and SA treatment. Unlike SISWI3C, the expression of SISWI3A and SISWI3B was not changed under SA treatment (Figure 3B). Interestingly, the transcript of SISWI3D showed no difference under all treatments compared to control (Figure 3B). These results revealed that SISWI3A, SISWI3B, and SISWIC may be involved in response to different environmental stimuli in tomato.

\subsection{Members of SlSWI3s Interact with Other Proteins}

In Arabidopsis, yeast-two-hybrid screens showed that AtSWI3A and AtSWI3B interact with the MADS-box transcriptional factors AGL18 (AGAMOUS-LIKE 18) and AGL73 [33]. In addition, AtSWI3A and AtSWI3B form homodimers and heterodimers and interact with BSH/SNF5 [20], while AtSWI3B and AtSWI3C form heterodimers and interact with the Snf2-like protein BRM (the ATPase of the SWI/SNF chromatin-remodeling complex) [18,34]. Thus, to explore whether SISWI3s showed the similar interaction pattern, yeast-two-hybrid assays were performed. Like AtSWI3A and AtSWI3B, SISWI3A, and SISWI3B can also form heterodimers and homodimers (Figure 4A, Figure S2). In addition, SISWI3B also interacted with SISWI3C in yeast cells (Figure 4A). The interactions of SISWI3s with the SIRIN and the Snf2-like protein SICHR8 were also analyzed. Indeed, SIRIN is encoded by a member of the SEPALLATA4 (SEP4) clade of MADS-box genes [35], which function as a master regulator of the ripening process in tomato. SICHR8 displays high sequence homology with BRM in Arabidopsis [36], and overexpression of SICHR8 in tomato resulted in considerably compacter growth including significantly shorter roots and hypocotyls as well as reduced cotyledon and fruit size [37]. The yeast-two-hybrid assay showed that SIRIN interacted with SISWI3A, SISWI3B, and SISWI3C, 
while SICHR8 only interacted with SISWI3B (Figure 4A, Figure S2). Intriguingly, the yeast-two-hybrid assay also indicated that SISWI3C can interacte with Arabidopsis SWI3A, SWI3B, and SWI3D, respectively (Figure S3). Taken together, these results suggested that the function of SWI3s may be conserved in tomato and Arabidopsis.

A

DDO QDO QDO/X

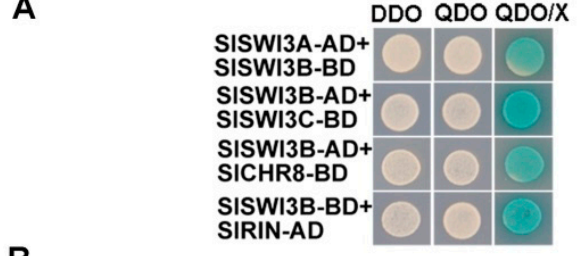

B

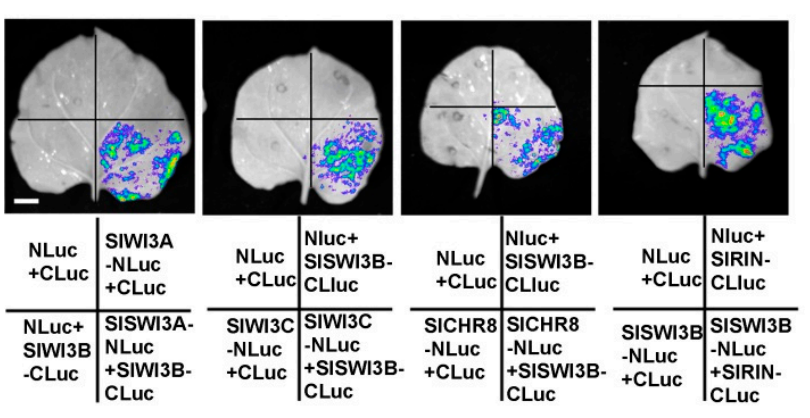

C

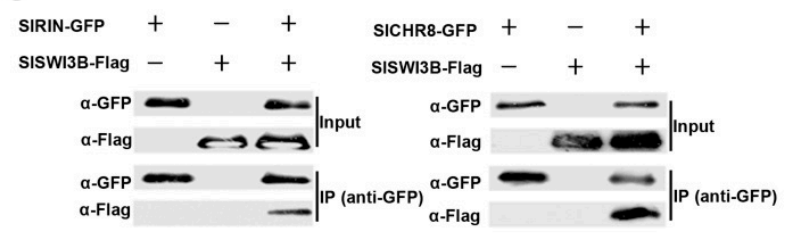

Figure 4. SISWI3s interacted with SISWI3A, SISWI3C SIRIN, and SICHR8 proteins. (A) SISWI3B interacted with SISWI3A, SISWI3C SIRIN and SICHR8 in yeast-two-hybrid assays. SISWI3B was either cloned into pGBKT7 or pGADT7 vectors, whereas SISWI3A, SISWI3C and SICHR8 were cloned into pGBKT7 vector, and SIRIN was cloned into PGADT7 vectors, respectively. Different constructs were cotransformed into the yeast strain AH109. The transformants were grown on the selective minimal medium without Leu and Trp (DDO). The transformants were also plated on QDO or QDO/X to test for possible interaction. QDO, SD/-Leu/-Trp/-His/-Ade. X, $\mathrm{x}$-a-gal. The same results were obtained in three independent experiments, and one representative result was shown. (B) SISWI3B interacted with SISWI3A, SISWI3C SIRIN and SICHR8 by LCI assay. The A. tumefaciens carrying the indicated construct pairs were injected into tobacco leaves, and the luciferase activities were measured $2 \mathrm{~d}$ after injection. Similar results were obtained in three independent experiments, and one representative result was shown. Bars $=0.5 \mathrm{~cm}$. (C) SISWI3B interacted with SIRIN and SICHR8 by Co-IP assay.The SISWI3B and SIRIN (or SICHR8) were subcloned into the pHB (Flag tag) and pEAQ-GFP (GFP tag) vector, respectively.These constructs were co-transformed into tobacco cells by Agrobacterium mediated infiltration. Transiently expressed SISWI3B-Flag and SIRIN-GFP (or SICHR8-GFP) were immunoprecipitated with an anti-GFP antibody, and then detected by western-blotting assay with an anti-Flag antibody.

To confirm their interaction in plant cells, SISWI3A, SISWI3B, SISWI3C, SIRIN and SICHR8 were fused with Nluc or Cluc and coexpressed in tobacco leaves and subjected for firefly luciferase complementation imaging assays. Consistent with the yeast-two-hybrid results, strong LUC activity was observed when Cluc-SISWI3B and SISWI3A-Nluc/or SISWI3C-Nluc/or SICHR8-Nluc were coexpressed (Figure 4B). Similar results were also observed when SISWI3B-Nluc and CLuc-SIRIN were coexpressed in tobacco leaves (Figure 4B). Next, the interaction of SISWI3B with SIRIN and SICHR8 was examined by co-immunoprecipitation (Co-IP) assays. We transiently expressed SISWI3B, SIRIN and SICHR8 
proteins in tobacco. The SISWI3B fused with three FLAG tags (pHB-SISWI3B) and SIRIN (or SICHR8) fused with a GFP tag (pEAQ-SIRIN) constructs were co-transformed into tobacco epidermal cells by Agrobacterium-mediated infiltration assays. The anti-GFP antibody (GFP-Trap ${ }^{\circledR} \_$A beads) was used for immunoprecipitation, and the immunoprecipitated protein was then analyzed by western-blotting assays using an anti-Flag antibody. We showed that SISWI3B-FLAG protein was co-immunoprecipitated by SIRIN-GFP or SICHR8-GFP (Figure 4C). Collectively, these data supported that SISWI3B interacts with SISWI3A, SISWI3C, SICHR8, and SIRIN both in vivo and in vitro.

\subsection{Ectopic Overexpression of SISWI3C Enhances Leaf Growth}

In Arabidopsis, overexpression of SWI3C frequently leads to an increase in rosette area [26]. To further analyze their functions, SISWI3A, SISWI3B, SISWI3C, and SISWI3D were ectopically expressed in Arabidopsis plants driven by the $35 \mathrm{~S}$ promoter. The independent hygromycin-resistant $\mathrm{T}_{1}$ transformants were transferred into soil and grown in a greenhouse and self-pollinated to obtain segregated $\mathrm{T}_{2}$ progeny for genetic analysis. All overexpression lines showed a 3:1 segregation pattern for hygromycin resistance, and three homozygous lines were selected for further analysis. As for SISWI3C, all these selected lines showed increased expression of SISWI3C (Figure S4). Phenotypic analysis showed that the 21-day-old soil-grown seedlings of 35S:SISWI3C 1, 35S:SlSWI3C 2 and 35S:SISWI3C 3 were much larger than Col-0 (Figure 5A). Consistent with this observation, 35S:SlSWI3C 1, 35S:SISWI3C 2 and 35S:SISWI3C 3 plants had significantly larger rosette leaves (Figure 5B). In addition, the surface area of the $5^{\text {th }}$ rosette leaf of 35S:SISWI3C 1, 35S:SISWI3C 2 and 35S:SISWI3C 3 is $38.2,46.04$, and $46.08 \mathrm{~mm}^{2}$, respectively, which were significantly larger than that of Col-0 (Figure 5C). Consistent with the larger leaves, the fresh weights (FW) of up-ground parts of all SISWI3C overexpressing plants was increased when compared with Col-0 plants (Figure S5). In contrast, transgenic Arabidopsis plants overexpression of SISWI3A, SISWI3B, and SISWI3D showed no visible phenotypes including the rosette sizes compared with Col-0 (Figure S4, Figure S6).
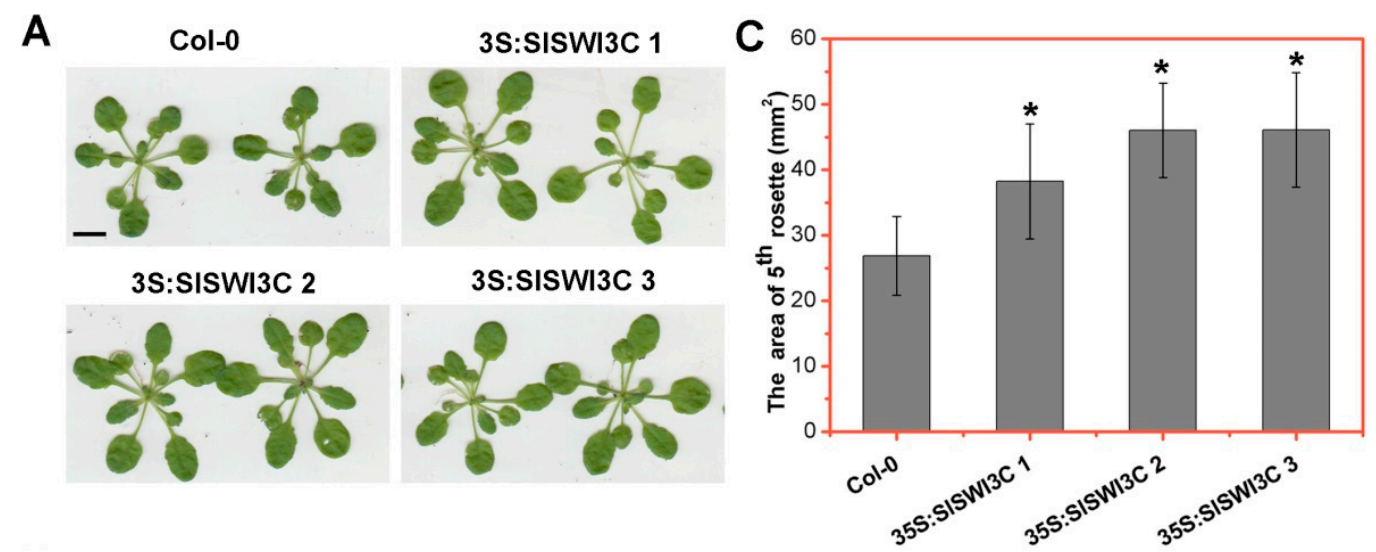

Figure 5. Cont. 
B

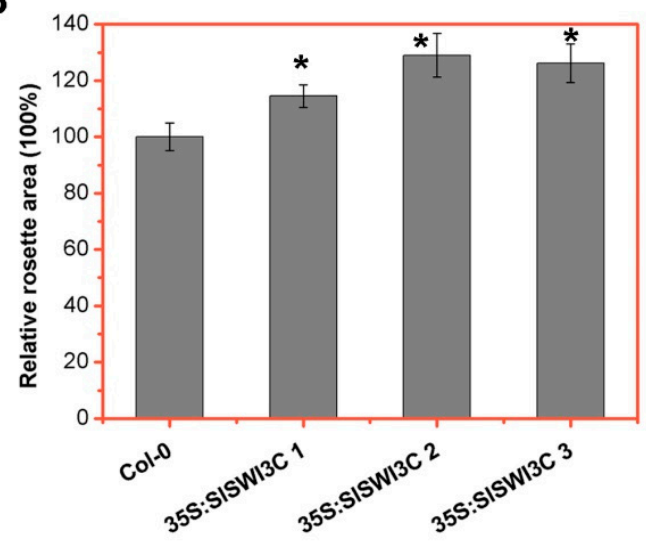

D

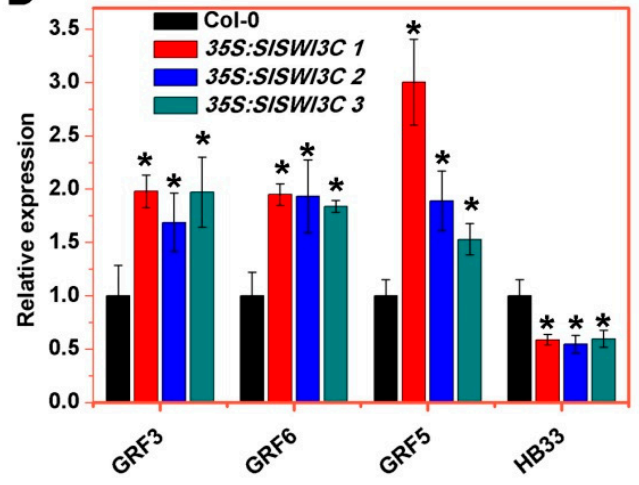

Figure 5. Overexpression of SISWI3C enhances leaf growth. (A) Rosettes of 21-d-old Col-0 and 35S:SISWI3C lines showing enhanced leaf growth. Three experiments were repeated with similar results, and one representative result was shown. Bar $=0.5 \mathrm{~cm}$. (B, C) Total (B) and 5th rosette (C) area calculated using ImageJ (http://rsb.info.nih.gov/ij/) software. The individual leaf from 21-d-old Col-0 and 35S:SlSWI3Cs plants was photographed and calculated using ImageJ. Error bars are SE $(n=15)$. Asterisks indicate significant difference from the Col- $0(p<0.05$, Student's $t$ test). The data are representative from three independent experiments. (D) SISWI3C promotes the expression of GRFs in Arabidopsis. Expression levels determined by qRT-PCR in 21-d-old Col-0 and 35S:SlSWI3Cs rosettes grown in long-day ( $16 \mathrm{~h}$ light $/ 8 \mathrm{~h}$ dark) conditions. qRT-PCR was amplified using gene-specific primers. The ACTIN2 (AT3G18780) was used as an internal control. Error bars are SE. Asterisks indicate significant difference from wild-type plants ( $p<0.05$, Student's $t$ test). The data are representative from three independent experiments.

Next, we determined the role of SISWI3C in the expression of the genes related to leaf development. As shown in Figure 5D, the expression levels of GROWTH REGULATING FACTOR 3 (GRF3), GRF5, and GRF6 were significantly increased in 21-day-old 35S:SlSWI3Cs shoots grown in long-day conditions compared with Col-0 (Figure 5D). GRFs are comprised of nine members (GRF1 to GRF9) [38] and stimulate leaf cell proliferation, since overexpression of GRF1, GRF2, and GRF5 enhances leaf growth and cell division $[39,40]$. Thus, the increased expression of GRFS in 35S:SISWI3Cs may be responsible for the larger leaf size. Intriguingly, HB33, a gene that is upregulated in brm mutants [26], was significantly downregulated in 35S:SISWI3Cs plants (Figure 5D).

\section{Discussion}

As one of the subunit of CRCs, SWI3 plays key roles in different cellular process in eukaryotic cells. In yeast, the SWI-SNF assembly and ATP-dependent H2A-H2B displacement are controlled by Swi3p [11,12]. Human BAF170 (SMARCC2) and BAF155 (SMARCC1), the homologs of Swi3p, are involved in cancers since BAF170 and BAF155 mutations were found in gastric and colorectal cancers and small cell lung cancers, respectively [41,42]. In Arabidopsis, both AtSWI3A and AtSWI3B are essential for early embryonic development, whereas AtSWI3C and AtSWI3D affect different phases of vegetative and reproductive development [20]. In this study, we identified four SWI3-like proteins in tomato: SWI3A, SWI3B, SWI3C, and SWI3D (Table 1, Figure 1A). Intriguingly, there are 6 SWI3-like proteins in rice (Table 1, Figure 1A) and 7 SWI3-like proteins in maize [27], indicating more SWI3-like proteins present in monocot. The fact that more SWI3 homologs exist in monocot may suggest the functional diversification of SWI3 paralogs in monocot.

All SISWI3s contain the typical SWIRM and SANT domains (Figure 1B). The SWIRM domain forms a compact helix-turn-helix (HTH)-related structure and mediates specific protein-protein interactions [15], while the SANT domain, which is characterized by its homology to the DNA binding domain of c-myb, functions as a histone tail binding module [17,43]. In addition to SWIRM and SANT domains, a SWIRM-assoc_1 domain was found in the C-terminus of SISWI3s (Figure 1B). A leucine 
zipper domain located on the C-terminus of SWI3s [20] is involved in the interaction between SWI3s, since human BAF155 and BAF170 form heterodimers (BAF155/BAF170) or homodimers (BAF155/155 or BAF170/170) through the leucine zipper domain [44]. The sequences of the SWIRM-assoc_1 domain are larger than that of leucine zipper domain and the function of the SWIRM-assoc_1 domain is still unclear. Similar to the Arabidopsis AtSWI3B [21], all SISWI3s are also localized in the nucleus (Figure 2), which is consistent with their roles as the subunits of CRCs.

The tissue-specific and stress-responsive expression patterns may be a useful way to explore gene functions. The expression profiles of SISWI3s suggested that some SISWI3s may play a similar role with their homologs in Arabidopsis. For instance, SISWI3C is mainly expressed in roots and reproductive organs (Figure 3A), indicating that it functions in root and reproductive development [20]. Furthermore, functional divergence was also observed between SISWI3B and its homolog AtSWI3B, since $S I S W I 3 B$ is only poorly expressed in leaves (Figure 3A), whereas AtSWI3B is highly expressed in this organ [45], and knock-down of $A t S W I 3 B$ results in an upward-curling leaf phenotype [24]. In addition, we found that the expression of SISWI3A and SISWI3B is induced by cold treatment, while SISWI3C is strongly repressed by ABA, salt and SA treatment (Figure 3B). These data indicate that some SICHRs may also respond to environmental stimuli.

In Arabidopsis, AtSWI3A and AtSWI3B can form homodimers and heterodimers, AtSWI3C can form heterodimers with both AtSWI3A and AtSWI3B, whereas AtSWI3D can form heterodimers only with AtSWI3B [18,20], suggesting their functional together in a complicated controlling network. In addition, AtSWI3B interacts with BSH/SNF5 and BRM, two core subunits of the SWI/SNF chromatin-remodeling complex [20,34]. Consistent with these data, our results also showed that SISWI3A and SISWI3B can form heterodimers and homodimers, whereas SISWI3B and SISWI3C can form heterodimers (Figure 4, Figure S2). Moreover, SISWI3C can also form heterodimers with AtSWI3s (Figure S3), and interacts with SICHR8, the Arabidopsis homolog of BRM. Collectively, these data suggested that CRCs in Arabidopsis and tomato may have similar functions. Nevertheless, the interaction between SISWI3s (SISWI3A, SISWI3B, and SISWI3C) with the MADS-box protein SIRIN (Figure 4, Figure S2) indicated that SISWI3s may be involved in fruit ripening in tomato.

Previous studies showed that $A t S W I 3 B$ is essential for early embryonic development and ABA signaling [20,21], while AtSWI3C and AtSWI3D play important roles in vegetative and reproductive development [20] as well as GA signaling [25]. Mutations of AtSWI3C cause leaf curling and reduced fertility, while mutations of AtSWI3D lead to leaf curling, severe dwarfism, and alteration in the number and development of flower organs with complete male and female sterility [20]. Moreover, over-expression of $A t S W I 3 C$ increases the leaf size due to increased cell numbers [26]. AtSWI3B is also involved in leaf development via regulating IAMT1, which encodes a carboxyl methyltransferase in the auxin metabolism [24]. Intriguingly, the maize SWI3D-like gene $\mathrm{ZmCHB101}$ knock-down lines also show curling leaves and impaired development in reproductive tissues, such as significant reduction of spikelet numbers and smaller and lighter ears compared to WT [27]. Collectively, these observations indicated that the physiological functions of SWI3s may be evolutionarily conserved in different plant species.

Like AtSWI3C, over-expression of SISWI3C also resulted in the increased leaf size in transgenic Arabidopsis (Figure 5A-C). The expression of GRF3, GRF5, and GRF6 was significantly increased in SISWI3C overexpressing seedlings (Figure 5D). These data suggested that the bigger leaf size of over-expression SISWI3C transgenic Arabidopsis may be caused by the increased expression of GRFs, since overexpression of GRF1, GRF2, and GRF5 enhances leaf growth and cell division $[39,40]$. Nevertheless, transgenic Arabidopsis seedlings overexpression of SISWI3A, SISWI3B, and SISWI3D showed no difference in the rosette sizes compared with Col-0 (Figure S5), suggesting that SISWI3C may function differently from other SISWI3 proteins. Taken together, our results indicated that the functions of SWI3C may, at least in some developmental processes, be conserved in tomato and Arabidospis. Further in-depth analysis using transgenic tomato is required to investigate the functions of SISWI3s in tomato development. 


\section{Materials and Methods}

\subsection{Plant Materials and Growth Conditions}

Solanum lycopersicum cultivar "Heinz 1706" was used in this study. Surface-sterilized tomato seeds were grown in the Murashige and Skoog (MS) medium with 1.5\% sucrose and $0.8 \%$ agar for 14 days in a controlled environment greenhouse with a long photoperiod ( $16 \mathrm{~h}$ light/ $8 \mathrm{~h}$ dark) at $23 \pm 1{ }^{\circ} \mathrm{C}$.

For hormone and stress treatments, 14-day-old "Heinz 1706" seedlings grown in the MS medium were transferred to the liquid MS medium containing SA $(5 \mathrm{mM}), \mathrm{ABA}(100 \mu \mathrm{M})$, and $\mathrm{NaCl}(200 \mathrm{mM})$ for $2 \mathrm{~h}$, respectively. For cold stress test, the plates were transferred to a $4{ }^{\circ} \mathrm{C}$ growth cabinet for $2 \mathrm{~h}$. After treatment, the seedlings were harvested and immediately frozen in liquid nitrogen for further gene expression. The seedlings without treatment (seedlings grown in the MS medium) were used as control. For each treatment, about 10 seedlings were used for RNA extraction.

\subsection{Identification of Tomato Swi3-Like Genes and Phylogenetic Tree Construction}

The AtSWI3A, AtSWI3B, AtSWI3C and AtSWI3D sequences of Arabidopsis thaliana and yeast $\mathrm{ScSWI} 3$ were used to perform a search in the Solamum lycopersicum genome using the BLASTP program in the SGN (http://solgenomics.net/). Then, the candidates of Swi3-like proteins were confirmed using the HMMER-based SMART (http://smart.embl-heidelberg.de/) and Pfam (http://pfam.xfam.org/) programs. The domain architecture was drawn using DOG2.0 software [46].

The Swi3-like protein sequences from tomato, Arabidopsis, rice (O. sativa), yeast (S. cerevisiae), fruit fly (D. melanogaster) and human (H. sapiens) were aligned with ClustalW, and the alignment was imported in MEGA5.2 for phylogenetic generation using Neighbor-Joining method [47].

\subsection{Subcellular Localization Assays}

The subcellular localizations of SISWI3s were first predicted using the WoLFPSORT (http://www. genscript.com/psort/wolf_psort.html), Plant-mPLoc (http://www.csbio.sjtu.edu.cn/bioinf/plant-multi/\#) and Euk-mPLoc 2.0 (http://www.csbio.sjtu.edu.cn/bioinf/euk-multi-2/) programs, and confirmed by GFP-tagged transient expression assays in tobacco (Nicotiana benthamiana) leaves [31]. The full length CDS of SISWI3s were subcloned into the pEAQ-GFP vector (the C-terminus of SISWI3s was fused with GFP) [48], and all the constructs were subsequently transformed into Agrobacterium tumefaciens strain GV3103. After grown in LB medium at $28^{\circ} \mathrm{C}$ overnight, bacterial suspensions were infiltrated into young but fully expanded leaves of tobacco using a needleless syringe. After infiltration, plants were immediately covered with plastic bags and placed at $23^{\circ} \mathrm{C}$ for $48 \mathrm{~h}$ before bag removal. The distribution of the fusion protein was determined using a confocal fluorescence microscope. To locate the fluorescent proteins in nuclei, the tobacco leaves were infiltrated with PBS containing $4^{\prime}$, 6-diamidino-2-phenylindole (DAPI, $1 \mu \mathrm{g} / \mathrm{mL}$ ). Three independent experiments were repeated to confirm results.

\subsection{Yeast-Two-Hybrid Assay}

Yeast-two-hybrid assays were performed according to the manufacturer's instructions for the Matchmaker GAL4-based two-hybrid system 3 (Clontech, Takara, Dalian, China). SlSWI3s, SlCHR8 and SIRIN were cloned into the pGBKT7 or pGADT7 vectors. Protein interactions were tested by stringent (SD/-Leu/-Trp/-His/-Ade) selection supplied with $\beta$-galactosidase activity measurement (Clontech, Takara, Dalian, China). Three independent experiments were repeated to confirm results.

\subsection{LCI Assay}

Luciferase complementation imaging (LCI) assays were performed as described previously [49]. The CDS of SISWI3A, SISWI3B, SISWI3C, SICHR8, and SIRIN was cloned into either pCAMBIA-Nluc or pCAMBIA-Cluc. All the constructs were transformed into A. tumefaciens strain GV3103. An equal 
volume of A. tumefaciens harboring pCAMBIA-NLuc and pCAMBIA-CLuc (or their derivative constructs) was mixed to a final concentration of $\mathrm{OD}_{600}=1.0$. Four different combinations of A. tumefaciens were infiltrated into four different positions at the same leaves of tobacco. Plants were placed in $23^{\circ} \mathrm{C}$ and allowed to recover for $60 \mathrm{~h}$. A low-light cooled CCD imaging apparatus (NightOWL II LB983 with indiGO software) was used to capture the LUC image. Three independent experiments were repeated to confirm results.

\subsection{Co-Immunoprecipitation (Co-IP) Assays}

Co-IP assays were performed as described previously [50]. Two days after infiltration, tobacco leaves were harvested and ground to a fine powder in liquid nitrogen. Proteins were extracted in an extraction buffer ( $50 \mathrm{mM}$ Tris- $\mathrm{HCl}, \mathrm{pH} 7.4,150 \mathrm{mM} \mathrm{NaCl}, 2 \mathrm{mM} \mathrm{MgCl} 2,1 \mathrm{mM} \mathrm{DTT}, 20 \%$ glycerol, and $1 \%$ NP-40) containing protease inhibitor cocktail (Roche, Shanghai, China). Cell debris was pelleted by centrifugation at $14,000 \times g$ for $20 \mathrm{~min}$. The supernatant was incubated with $30 \mu \mathrm{L}$ of GFP-Trap ${ }^{\circledR}$ _A beads (Chromo Tek, Martinsried, Germany) at $4{ }^{\circ} \mathrm{C}$ for $4 \mathrm{~h}$, then the beads were centrifuged and washed six times with a washing buffer $(50 \mathrm{mM}$ Tris- $\mathrm{HCl}, \mathrm{pH} 7.4,150 \mathrm{mM} \mathrm{NaCl}, 2 \mathrm{mM}$ $\mathrm{MgCl}_{2}, 1 \mathrm{mM} \mathrm{DTT}, 10 \%$ glycerol, and $1 \% \mathrm{NP}-40$ ). Proteins were eluted with $40 \mu \mathrm{L}$ of $2 \times$ loading buffer and analyzed by western blotting using anti-GFP (Roche, Shanghai, China) and anti-Flag antibodies (LifeTein, Beijing, China).

\subsection{RNA Extraction and Expression Analyses}

Total RNA was isolated using Trizol Reagent (Invitrogen, Shanghai, China) according to the manufacturer's protocol. cDNAs were synthesized from $2 \mu \mathrm{g}$ of total RNA using the TransScript ${ }^{\mathrm{TM}}$ One-Step gDNA Removal and cDNA Synthesis Supermix kit (TransGenBiotech, Guangzhou, China). Real-Time PCR was performed with iTaq ${ }^{\mathrm{TM}}$ Universal SYBR $^{\circledR}$ Green Supermix (BIO-RAD, Shanghai, China) using ABI7500 Fast Real-Time PCR system. The gene-specific primers for real-time PCR were designed by PrimerQuest Tool (https://sg.idtdna.com/ Primerquest/Home/Index) and listed in Table S1. The Arabidopsis ACTIN2 (AT3G18780) and tomato ACTIN (Solyc03g078400) were used as a reference gene. Three independent sets of biological replicates were conducted with two technical replicates to confirm results.

For tissue and organ specific expression profiles, the expression data of tomato SlSWI3s were extracted from publicly available RNA-seq datasets from the Tomato Genome Consortium [32] and visualized with Matrix2PNG (https://matrix2png.msl.ubc.ca/bin/matrix2png.cgi) [51]. The publicly available RNA-seq data were obtained from transcriptome sequencing using three-week-old sand-grown seedlings, roots, leaves, buds (unopened flower buds), and flowers (fully open flowers) as well as fruits (at $1 \mathrm{~cm}, 2 \mathrm{~cm}$, and $3 \mathrm{~cm}$ ), MG (mature green), breaker ( $\mathrm{Br}$, early ripening), and 10-day post-breaker (B + 10, red ripe) stages of tomato "Heinz 1706" [32]. The expression data of SlSWI3s were normalized to have mean zero and variance one before producing the heat maps.

\subsection{Generation of Transgenic Plants}

To construct the SISWI3C and SISWI3D overexpression vectors, the CDS without a stop codon of SISWI3C and SISWI3D were cloned into the plasmid pHB-flag containing the 35S promoter [52]. The constructed plasmids were separately transformed into the $A$. tumefaciens strain GV3103 by the heat shock method. The bacteria carrying different constructs were used to transform WT (Col-0) plants via floral dip transformation.

Leaf areas were measured with ImageJ (http://rsb.info.nih.gov/ij/) using three-week-old seedlings grown in soil (the same stage seedlings were also for RNA isolation) after dissection of individual leaves. Rosette areas were calculated as the sum of the individual leaf areas. Three independent sets of biological replicates were conducted to confirm results. 


\section{Conclusions}

In this study, four Swi3-like proteins, SISWI3A, SISWI3B, SISWI3C, and SISWI3D, were identified from tomato. All SISWI3s contain two characteristic domains: SWIRM and SANT domains, and are localized in the nucleus. All SISWI3s are ubiquitously expressed in all tissues and organs, and SISWI3A and SISWI3B can be induced by cold treatment. In addition, SISWI3B forms homodimers with itself and heterodimers with SISWI3A and SISWI3C. SISWI3B also interacts with SIRIN and SICHR8, two proteins associated with tomato reproductive development, indicating that SISWI3B may be involved in gene regulation in reproductive development. Furthermore, over-expression of SISWI3C increases the leaf size in transgenic Arabidopsis with increased expression of GRF3, GRF5 and GRF6.

Supplementary Materials: Supplementary materials can be found at http://www.mdpi.com/1422-0067/20/20/ 5121/s1. Figure S1. The subcellular localization of tomato SWI3-like proteins. Figure S2. Self-activation (A) and the interactions of SISWI3s with each other (B) were examined in yeast cells. Figure S3. The interactions of SISWI3s with AtSWI3s were examined in yeast cells. Figure S4. The transcripts of SISWI3s in 21-day-old transgenic Arabidopsis seedlings. Figure S5. The fresh weights (FW) of up-ground parts of Col-0 and SISWI3C overexpressing plants grown in soil for two weeks. Figure S6. The phenotype of overexpression of SISWI3A, SISWI3B, and SISWI3D transgenic Arabidopsis seedlings.

Author Contributions: Z.Z., T.L., and X.P. performed the research, Z.Z., T.L., and S.Y. analyzed data. S.Y. and K.W. conceived the idea and revised and organized the manuscript.

Funding: This work was supported by the Guangdong Natural Science Funds for Distinguished Young Scholars (2016A030306047); Pearl River S\&T Nova Program of Guangzhou (201610010138); the Youth Innovation Promotion Association, CAS (2017398); the Science and Technology Program of Guangzhou (201607010270) and the National Natural Science Foundation of China (No. 31672161). Modern Agricultural Innovation Team Project of Guangdong Province (2018LM2150, 2019KJ106); Guangdong Academy of Agricultural Sciences Foundation (201630TD).

Acknowledgments: We are grateful to Yawen Lei (SUN YAT-SEN UNIVERSITY) and Lomonossoff (Department of Biological Chemistry, John Innes Centre, Norwich, UK) for providing the pHB and pEAQ-GFP plasmids.

Conflicts of Interest: The authors declare no conflict of interest.

\section{References}

1. Luger, K.; Mader, A.W.; Richmond, R.K.; Sargent, D.F.; Richmond, T.J. Crystal structure of the nucleosome core particle at 2.8 A resolution. Nature 1997, 389, 251-260. [CrossRef] [PubMed]

2. Henikoff, S.; Shilatifard, A. Histone modification: Cause or cog? Trends in Genet. 2011, 27, 389-396. [CrossRef] [PubMed]

3. Jerzmanowski, A. SWI/SNF chromatin remodeling and linker histones in plants. Biochim. Biophys. Acta 2007, 1769, 330-345. [CrossRef] [PubMed]

4. Imbalzano, A.N. Energy-dependent chromatin remodelers: Complex complexes and their components. Crit. Rev. Eukaryot. Gene Expr. 1998, 8, 225-255. [CrossRef]

5. Clapier, C.R.; Cairns, B.R. The Biology of Chromatin Remodeling Complexes. Annu. Rev. Biochem. 2009, 78, 273-304. [CrossRef]

6. Neigeborn, L.; Carlson, M. Genes Affecting the Regulation of Suc2 Gene-Expression by Glucose Repression in Saccharomyces-Cerevisiae. Genetics 1984, 108, 845-858.

7. Peterson, C.L.; Herskowitz, I. Characterization of the Yeast Swi1, Swi2, and Swi3 Genes, Which Encode a Global Activator of Transcription. Cell 1992, 68, 573-583. [CrossRef]

8. Cairns, B.R.; Kim, Y.J.; Sayre, M.H.; Laurent, B.C.; Kornberg, R.D. A Multisubunit Complex Containing the Swi1/Adr6, Swi2/Snf2, Swi3, Snf5, and Snf6 Gene-Products Isolated from Yeast. Proc. Natl Acad. Sci. USA 1994, 91, 1950-1954. [CrossRef]

9. Phelan, M.L.; Sif, S.; Narlikar, G.J.; Kingston, R.E. Reconstitution of a core chromatin remodeling complex from SWI/SNF subunits. Mol. Cell 1999, 3, 247-253. [CrossRef]

10. Johnson, C.N.; Adkins, N.L.; Georgel, P. Chromatin remodeling complexes: ATP-dependent machines in action. Biochem. Cell Biol. 2005, 83, 405-417. [CrossRef]

11. Yang, X.F.; Zaurin, R.; Beato, M.; Peterson, C.L. Swi3p controls SWI/SNF assembly and ATP-dependent H2A-H2B displacement. Nat. Struct. Mol. Biol. 2007, 14, 540-547. [CrossRef] [PubMed] 
12. Dechassa, M.L.; Zhang, B.; Horowitz-Scherer, R.; Persinger, J.; Woodcock, C.L.; Peterson, C.L.; Bartholomew, B. Architecture of the SWI/SNF-nucleosome complex. Mol. Cell Biol. 2008, 28, 6010-6021. [CrossRef] [PubMed]

13. Hu, Z.Z.; Killion, P.J.; Iyer, V.R. Genetic reconstruction of a functional transcriptional regulatory network. Nat. Genet. 2007, 39, 683-687. [CrossRef] [PubMed]

14. Euskirchen, G.M.; Auerbach, R.K.; Davidov, E.; Gianoulis, T.A.; Zhong, G.N.; Rozowsky, J.; Bhardwaj, N.; Gerstein, M.B.; Snyder, M. Diverse Roles and Interactions of the SWI/SNF Chromatin Remodeling Complex Revealed Using Global Approaches. Plos Genet. 2011, 7, e1002008. [CrossRef]

15. Aravind, L.; Iyer, L.M. The SWIRM domain: A conserved module found in chromosomal proteins points to novel chromatin-modifying activities. Genome Bio. 2002, 3. [CrossRef]

16. Aasland, R.; Stewart, A.F.; Gibson, T. The SANT domain: A putative DNA-binding domain in the SWI-SNF and ADA complexes, the transcriptional corepressor N-CoR and TFIIIB. Trends Biochem. Sci. 1996, 21, 87-88. [CrossRef]

17. Boyer, L.A.; Langer, M.R.; Crowley, K.A.; Tan, S.; Denu, J.M.; Peterson, C.L. Essential role for the SANT domain in the functioning of multiple chromatin remodeling enzymes. Mol. Cell 2002, 10, 935-942. [CrossRef]

18. Sarnowski, T.J.; Swiezewski, S.; Pawlikowska, K.; Kaczanowski, S.; Jerzmanowski, A. AtSWI3B, an Arabidopsis homolog of SWI3, a core subunit of yeast Swi/Snf chromatin remodeling complex, interacts with FCA, a regulator of flowering time. Nucleic Acids Res. 2002, 30, 3412-3421. [CrossRef]

19. Zhou, C.H.; Miki, B.; Wu, K.Q. CHB2, a member of the SWI3 gene family, is a global regulator in Arabidopsis. Plant Mol. Biol. 2003, 52, 1125-1134. [CrossRef]

20. Sarnowski, T.J.; Rios, G.; Jasik, J.; Swiezewski, S.; Kaczanowski, S.; Li, Y.; Kwiatkowska, A.; Pawlikowska, K.; Kozbial, M.; Kozbial, P.; et al. SWI3 subunits of putative SWI/SNF chromatin-remodeling complexes play distinct roles during Arabidopsis development. Plant Cell 2005, 17, 2454-2472. [CrossRef]

21. Saez, A.; Rodrigues, A.; Santiago, J.; Rubio, S.; Rodriguez, P.L. HAB1-SWI3B Interaction Reveals a Link between Abscisic Acid Signaling and Putative SWI/SNF Chromatin-Remodeling Complexes in Arabidopsis. Plant Cell 2008, 20, 2972-2988. [CrossRef] [PubMed]

22. Zhu, Y.Y.; Rowley, M.J.; Bohmdorfer, G.; Wierzbicki, A.T. A SWI/SNF Chromatin-Remodeling Complex Acts in Noncoding RNA-Mediated Transcriptional Silencing. Mol. Cell 2013, 49, 298-309. [CrossRef] [PubMed]

23. Liu, Z.W.; Zhou, J.X.; Huang, H.W.; Li, Y.Q.; Shao, C.R.; Li, L.; Cai, T.; Chen, S.; He, X.J. Two Components of the RNA-Directed DNA Methylation Pathway Associate with MORC6 and Silence Loci Targeted by MORC6 in Arabidopsis. Plos Genet. 2016, 12, e1006026. [CrossRef] [PubMed]

24. Han, W.X.; Han, D.L.; He, Z.P.; Hu, H.; Wu, Q.; Zhang, J.J.; Jiang, J.M.; Qin, G.J.; Cui, Y.H.; Lai, J.B.; et al. The SWI/SNF subunit SWI3B regulates IAMT1 expression via chromatin remodeling in Arabidopsis leaf development. Plant Sci. 2018, 271, 127-132. [CrossRef] [PubMed]

25. Sarnowska, E.A.; Rolicka, A.T.; Bucior, E.; Cwiek, P.; Tohge, T.; Fernie, A.R.; Jikumaru, Y.; Kamiya, Y.; Franzen, R.; Schmelzer, E.; et al. DELLA-Interacting SWI3C Core Subunit of Switch/Sucrose Nonfermenting Chromatin Remodeling Complex Modulates Gibberellin Responses and Hormonal Cross Talk in Arabidopsis. Plant Physiol. 2013, 163, 305-317. [CrossRef] [PubMed]

26. Vercruyssen, L.; Verkest, A.; Gonzalez, N.; Heyndrickx, K.S.; Eeckhout, D.; Han, S.K.; Jegu, T.; Archacki, R.; Van Leene, J.; Andriankaja, M.; et al. ANGUSTIFOLIA3 Binds to SWI/SNF Chromatin Remodeling Complexes to Regulate Transcription during Arabidopsis Leaf Development. Plant Cell 2014, 26, 210-229. [CrossRef] [PubMed]

27. Yu, X.; Jiang, L.; Wu, R.; Meng, X.; Zhang, A.; Li, N.; Xia, Q.; Qi, X.; Pang, J.; Xu, Z.Y.; et al. The Core Subunit of a Chromatin-Remodeling Complex, ZmCHB101, Plays Essential Roles in Maize Growth and Development. Sci. Rep. 2016, 6, 38504. [CrossRef]

28. Gao, Y.; Yang, S.G.; Yuan, L.Y.; Cui, Y.H.; Wu, K.Q. Comparative Analysis of SWIRM Domain-Containing Proteins in Plants. Comp. Funct. Genom. 2012, 2012, 310402. [CrossRef]

29. Ponting, C.P.; Blake, D.J.; Davies, K.E.; KendrickJones, J.; Winder, S.J. ZZ and TAZ: New putative zinc fingers in dystrophin and other proteins. Trends Biochem. Sci. 1996, 21, 11-13. [CrossRef]

30. Legge, G.B.; Martinez-Yamout, M.A.; Hambly, D.M.; Trinh, T.; Lee, B.M.; Dyson, H.J.; Wright, P.E. ZZ domain of CBP: An unusual zinc finger fold in a protein interaction module. J. Mol. Biol. 2004, 343, 1081-1093. [CrossRef] 
31. Sparkes, I.A.; Runions, J.; Kearns, A.; Hawes, C. Rapid, transient expression of fluorescent fusion proteins in tobacco plants and generation of stably transformed plants. Nat. Protoc. 2006, 1, 2019-2025. [CrossRef] [PubMed]

32. Sato, S.; Tabata, S.; Hirakawa, H.; Asamizu, E.; Shirasawa, K.; Isobe, S.; Kaneko, T.; Nakamura, Y.; Shibata, D.; Aoki, K.; et al. The tomato genome sequence provides insights into fleshy fruit evolution. Nature 2012, 485, 635-641.

33. Efroni, I.; Han, S.K.; Kim, H.J.; Wu, M.F.; Steiner, E.; Birnbaum, K.D.; Hong, J.C.; Eshed, Y.; Wagner, D. Regulation of Leaf Maturation by Chromatin-Mediated Modulation of Cytokinin Responses. Dev. Cell 2013, 24, 438-445. [CrossRef] [PubMed]

34. Hurtado, L.; Farrona, S.; Reyes, J.C. The putative SWI/SNF complex subunit BRAHMA activates flower homeotic genes in Arabidopsis thaliana. Plant. Mol. Biol. 2006, 62, 291-304. [CrossRef] [PubMed]

35. Vrebalov, J.; Ruezinsky, D.; Padmanabhan, V.; White, R.; Medrano, D.; Drake, R.; Schuch, W.; Giovannoni, J.A. MADS-box gene necessary for fruit ripening at the tomato ripening-inhibitor (Rin) locus. Science 2002, 296, 343-346. [CrossRef]

36. Zhang, D.D.; Gao, S.J.; Yang, P.; Yang, J.; Yang, S.G.; Wu, K.Q. Identification and Expression Analysis of Snf2 Family Proteins in Tomato (Solanum lycopersicum). Int. J. Genom. 2019. [CrossRef]

37. Folta, A.; Bargsten, J.W.; Bisseling, T.; Nap, J.P.; Mlynarova, L. Compact tomato seedlings and plants upon overexpression of a tomato chromatin remodelling ATPase gene. Plant. Biotechnol. J. 2016, 14, 581-591. [CrossRef]

38. Kim, J.H.; Choi, D.S.; Kende, H. The AtGRF family of putative transcription factors is involved in leaf and cotyledon growth in Arabidopsis. Plant. J. 2003, 36, 94-104. [CrossRef]

39. Horiguchi, G.; Kim, G.T.; Tsukaya, H. The transcription factor AtGRF5 and the transcription coactivator AN3 regulate cell proliferation in leaf primordia of Arabidopsis thaliana. Plant. J. 2005, 43, 68-78. [CrossRef]

40. Kim, J.H.; Lee, B.H. GROWTH-REGULATING FACTOR4 of Arabidopsis thaliana is required for development of leaves, cotyledons, and shoot apical meristem. J. Plant. Biol. 2006, 49, 463-468. [CrossRef]

41. Kim, S.S.; Kim, M.S.; Yoo, N.J.; Lee, S.H. Frameshift mutations of a chromatin-remodeling gene SMARCC2 in gastric and colorectal cancers with microsatellite instability. Apmis 2013, 121, 168-169. [CrossRef] [PubMed]

42. Kadoch, C.; Hargreaves, D.C.; Hodges, C.; Elias, L.; Ho, L.; Ranish, J.; Crabtree, G.R. Proteomic and bioinformatic analysis of mammalian SWI/SNF complexes identifies extensive roles in human malignancy. Nat. Genet. 2013, 45, 592-601. [CrossRef] [PubMed]

43. Boyer, L.A.; Latek, R.R.; Peterson, C.L. The SANT domain: A unique histone-tail-binding module? Nat. Rev. Mol. Cell Biol. 2004, 5, 158-163. [CrossRef] [PubMed]

44. Wang, W.D.; Xue, Y.T.; Zhou, S.; Kuo, A.; Cairns, B.R.; Crabtree, G.R. Diversity and specialization of mammalian SWI/SNF complexes. Gene Dev. 1996, 10, 2117-2130. [CrossRef]

45. Winter, D.; Vinegar, B.; Nahal, H.; Ammar, R.; Wilson, G.V.; Provart, N.J. An “Electronic Fluorescent Pictograph" Browser for Exploring and Analyzing Large-Scale Biological Data Sets. PLoS ONE 2007, 2, e718. [CrossRef]

46. Ren, J.; Wen, L.P.; Gao, X.J.; Jin, C.J.; Xue, Y.; Yao, X.B. DOG 1.0: Illustrator of protein domain structures. Cell Res. 2009, 19, 271-273. [CrossRef]

47. Tamura, K.; Peterson, D.; Peterson, N.; Stecher, G.; Nei, M.; Kumar, S. MEGA5: Molecular Evolutionary Genetics Analysis Using Maximum Likelihood, Evolutionary Distance, and Maximum Parsimony Methods. Mol. Biol. Evol. 2011, 28, 2731-2739. [CrossRef]

48. Peyret, H.; Lomonossoff, G.P. The $\mathrm{pEAQ}$ vector series: The easy and quick way to produce recombinant proteins in plants. Plant. Mol. Biol. 2013, 83, 51-58. [CrossRef]

49. Chen, H.M.; Zou, Y.; Shang, Y.L.; Lin, H.Q.; Wang, Y.J.; Cai, R.; Tang, X.Y.; Zhou, J.M. Firefly luciferase complementation imaging assay for protein-protein interactions in plants. Plant. Physiol. 2008, 146, 368-376. [CrossRef]

50. Zhao, M.; Yang, S.; Chen, C.Y.; Li, C.; Shan, W.; Lu, W.; Cui, Y.; Liu, X.; Wu, K. Arabidopsis BREVIPEDICELLUS interacts with the SWI2/SNF2 chromatin remodeling ATPase BRAHMA to regulate KNAT2 and KNAT6 expression in control of inflorescence architecture. Plos Genet. 2015, 11, e1005125. [CrossRef]

51. Pavlidis, P.; Noble, W.S. Matrix2png: A utility for visualizing matrix data. Bioinformatics 2003, 19, $295-296$. [CrossRef] [PubMed] 
52. Mao, J.; Zhang, Y.C.; Sang, Y.; Li, Q.H.; Yang, H.Q. From The Cover: A role for Arabidopsis cryptochromes and COP1 in the regulation of stomatal opening. Proc. Natl. Acad. Sci. USA 2005, 102, 12270-12275. [CrossRef] [PubMed]

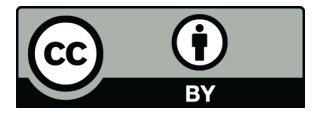

(C) 2019 by the authors. Licensee MDPI, Basel, Switzerland. This article is an open access article distributed under the terms and conditions of the Creative Commons Attribution (CC BY) license (http://creativecommons.org/licenses/by/4.0/). 